\title{
Tolerance for Disagreement for Students
}

\author{
Ivana Miloloža \\ Faculty of Teacher Education, University of Zagreb \\ Zagreb, Croatia \\ ivana.miloloza@gmail.com
}

Marin Milković

Media University, Koprivnica

Koprivnica, Croatia

marin.milkovic@medijsko-sveuciliste.hr

\author{
Ljubica Bakić-Tomić \\ Faculty of Teacher Education, University of Zagreb \\ Zagreb, Croatia \\ ljbakictomic@gmail.com
}

\author{
Vladimir Šimović \\ Media University, Koprivnica \\ Koprivnica, Croatia \\ simovic.vladimir@yahoo.com
}

\author{
Heri Bezić \\ Faculty of Economics, University of Rijeka \\ Rijeka, Croatia \\ bezic@efri.hr
}

Edmond Vlashaj

Vitrina University

Tirana, Albania

edmondvlashaj@yahoo.com

\begin{abstract}
The 16th of November has been declared in 1995 by the United Nations Organization for Education, Science and Culture (UNESCO) as the International Day of Tolerance, and the United Nations (UN) started a worldwide campaign with the goal of increasing tolerance. Tolerance means "respecting, accepting and acknowledging cultural differences and is the expression of our humanness. It is based on knowledge, openness, communication and freedom of thought, conscience and beliefs. A person's standpoint is considered tolerant if the person accepts the beliefs of others (even though they differ from his own) and accepts other behavioural patterns which differ from his own" [6]. A new Media university has been founded in Koprivnica in the Republic of Croatia, which offers three fields of specialisation: media design, media management and journalism. 147 students have enrolled in the university in 2012. The researchers wanted to determine the students' readiness to tolerate the standpoints of other people while disagreeing with them. "Tolerance for Disagreement Scale (TFD)" by James C. McCroskey [4] has been used in the research, which is a scale for measuring disagreement tolerance. The results show that the students of the Media university in Koprivnica tolerate disagreement during communication very well and that gender and age do not affect disagreement tolerance in any way.
\end{abstract}

Keywords-Media university students; measuring disagreement tolerance; cultural differences; accepting the beliefs of others; accepts other behavioural patterns

\section{INTRODUCTION}

The concept of tolerance comes from the Latin verb tolerare, which stands for "endure". It entails bearing and acknowledging different ideas, standpoints and lifestyles. To be tolerant means to be aware of the differences and to accept them in everyday life [2]. "A person's standpoint is considered tolerant if the person accepts the beliefs of others (even though they differ from his own) and accepts other behavioural patterns which differ from his own" [6].
In the social sense tolerance denotes an attitude toward someone (or something) and toward people, ideas and things, which at the very least tolerates their existence.

According to the UNESCO [9], the definition of tolerance is: "respecting, accepting and acknowledging differences between world cultures, our way of expression and what makes us human. It is based on knowledge, open-mindedness, communication and freedom of thought, conscience and standpoints. Tolerance is harmony among differences". The $16^{\text {th }}$ of November has been declared in 1995 by the UNESCO as the International Day of Tolerance, and the UN started a worldwide campaign with the goal of increasing tolerance.

When we speak about tolerance toward people, it obviously entails tolerance of different behavioural patterns, habits, standpoints, beliefs, appearances etc. [3].

Given the fact that people are not born as tolerant or intolerant and that both behavioural patterns need to be learned, people can quickly learn both and they are both necessary and useful. Perhaps in order to learn how to be tolerant not only certain general predispositions or learning environment are necessary, but also some prerequisites have to be fulfilled. One of such prerequisites is for instance empathy. It seems likely that a person who understands another person, despite of his background or race, can learn more easily to be tolerant than a person who considers other races as inferior, less sensitive or in any way different than he is [3].

"Apart from empathy, the existence of certain moral values, at the very least differentiation between right and wrong, as well as some specific knowledge, such as being familiar with basic human rights and basic common traits which exist among all people, can help the development of tolerance in the modern society" [3]. 
Batelaan and Gundara (1993; according to [1]) point out that: "communities have become more diverse, that is, we can observe the development of diversity and interdependency awareness. The urgent need for respect toward different cultures and awareness of common values has arisen, which are necessary for the development of democracy and application of social and human rights in practice." Already in 1959, the tenth principle of the Declaration about children's rights [7] states that: "a child should be educated in the spirit of understanding, tolerance, friendship among people, peace and universal brotherhood and with full awareness that his or her energy and talents need to be dedicated to other people". The International convention on economic, social and cultural rights [8] also states in article 13, paragraph 1, that education should: "enable everyone to efficiently act in a free society, promote understanding, tolerance and friendship among all nations and races, ethnic and religious groups and support the UN activities in maintaining peace". Thus all members of the UN are expected to educate children in the spirit of tolerance and in order to become tolerant.

\section{METHOD}

There are many causes for communication disagreements and some of the most common ones are different desires, needs and interests, different awareness and different standpoints and opinions on certain phenomena, problems and people.

The aim of this research was to determine how well an individual can tolerate other people when he disagrees with them. The research has been conducted among students who will in the future be working with the media and will need to communicate with a number of people. This research and its results are especially interesting for communication subjects and the results of the research can serve as an orientation tool for composing curriculums. In the future it might be used as one of the questionnaires given to the future students of this university as a part of their entrance exam.

The research has been conducted among all students of the university which have passed entrance exam, 147 in total (research sample). The Media university in Koprivnica is a university which has only recently been founded. Subjects who participated in this research have been first-year students of all three specialisation fields: journalism, media design and media management. The subjects' age ranged between 18 and 35 and the genders were more or less equally represented.

Research hypotheses are: $1^{\text {st }}$ hypothesis "the students studying at the Media university possess a high degree of disagreement tolerance, i.e. they are flexible and have a positive attitude toward disagreement"; $2^{\text {nd }}$ hypothesis "a statistically significant difference in disagreement tolerance with regard to the gender exists"; $3^{\text {rd }}$ hypothesis "a statistically significant difference in disagreement tolerance with regard to the age exists".

\section{A. Research Instrument}

A questionnaire which consisted of information on age and gender, as well as the "Tolerance of Disagreement Scale (TFD)" by James C. McCroskey [4], i.e. scale for measuring disagreement tolerance has been used (according to [5]). The scale consists of 15 statements written in Lickert style with possible answers: $5=$ I fully agree; $4=$ I agree; $3=$ I neither agree, nor disagree; 2 = I do not agree; 1 = I do not agree at all. The Cronbach's alpha coefficient for this questionnaire was 0.85. The questionnaire can be found in Appendix 1 .

\section{B. The Questionnaire}

The questionnaire has been distributed on paper among the aforementioned subjects. The research was anonymous and has been conducted in December 2012. The main dependent variable was attitude toward disagreement, i.e. the achieved score on the TFD, and independent variables were age and gender. Additional dependent variables were flexibility and disagreement tolerance level.

The purpose of the questionnaire was to achieve a certain score on the TFD. First the score for flexibility has been calculated so that answers to statements which deal with flexibility have been added (statements 1,2,5,7,8,14 and 15). Second, the answers to statements which show avoiding disagreement have been added (statements 3,4,6,9,10,11,12 and 13). Total attitude toward disagreement has been calculated in the following way, according to the recommendation of the author: disagreement tolerance $=48+$ flexibility result avoiding disagreement score. Total score which is higher than 46 shows high level of disagreement tolerance, 32-46 medium level and 32 low level.

\section{RESULTS}

TABLE I. RESEARCH SAMPLE CHARACTERISTICS

\begin{tabular}{|c|c|c|}
\hline \multicolumn{3}{|c|}{ Research Sample } \\
\hline \multirow{3}{*}{ Variable } & Percentage \\
\hline \multirow{3}{*}{ Gender } & Female & $59.90 \%$ \\
\cline { 2 - 3 } & Male & $40.10 \%$ \\
\hline \multirow{4}{*}{ Age } & $15-20$ & $59.90 \%$ \\
\cline { 2 - 3 } & $21-25$ & $34.00 \%$ \\
\cline { 2 - 3 } & $26-30$ & $5.40 \%$ \\
\cline { 2 - 3 } & $31-40$ & $0.70 \%$ \\
\hline
\end{tabular}

Research sample characteristics of the 147 students of the Media university in Koprivnica, with regard to gender and age, are shown in the Table I.

In order to be able to determine the further course of action and to be able to choose between the parametric and nonparametric approach, we have first tested the distribution normality of continuous variables. For that purpose we used the Kolmogorov Smirnov test (Table II.).

Results show that all distributions are statistically significantly different than the Gauss distribution except for the following variables: flexibility total score $(Z=1.33 ; \mathrm{p}>0.01)$, avoiding disagreement total score $(Z=1.28 ; \mathrm{p}>0.01)$ and disagreement tolerance $(\mathrm{Z}=0.87 ; \mathrm{p}>0.01)$. Based on the data outlined in Table II. We have decided to use the nonparametric statistics approach with all variables except for those which are normally distributed: flexibility total score, avoiding disagreement total score and disagreement tolerance, with which we have used parametric statistics. 
TABLE II. DISTRIBUTION NORMALITY OF CONTINUOUS VARIABLES AS MEASURED BY THE KOLMOGOROV SMIRNOV TEST

\begin{tabular}{|l|c|c|}
\hline \multicolumn{1}{|c|}{ Variable } & $\boldsymbol{Z}$ & $\boldsymbol{p}$ \\
\hline $\begin{array}{l}\text { 1. It is interesting for me to join a debate in } \\
\text { which there is a lot of disagreement. }\end{array}$ & 2.28 & $<0.01$ \\
\hline $\begin{array}{l}\text { 2. I enjoy talking to people who have } \\
\text { different standpoints than mine. }\end{array}$ & 2.61 & $<0.01$ \\
\hline $\begin{array}{l}\text { 3. I do not like to participate in } \\
\text { conversations in which there is a lot of } \\
\text { disagreement. }\end{array}$ & 2.73 & $<0.01$ \\
\hline $\begin{array}{l}\text { 4. I rather work in groups in which } \\
\text { everyone shares the same views as I do, } \\
\text { than in those in which people share } \\
\text { different views and standpoints. }\end{array}$ & 2.28 & $<0.01$ \\
\hline $\begin{array}{l}\text { 5. I believe that disagreement is generally } \\
\text { useful. }\end{array}$ & 2.44 & $<0.01$ \\
\hline $\begin{array}{l}\text { 6. I would rather change the subject when it } \\
\text { comes to disagreement. }\end{array}$ & 2.11 & $<0.01$ \\
\hline $\begin{array}{l}\text { 7. I have a tendency toward creating } \\
\text { disagreement because I believe it is useful. }\end{array}$ & 2.59 & $<0.01$ \\
\hline $\begin{array}{l}\text { 8. I enjoy quarrelling with people about } \\
\text { things we disagree on. }\end{array}$ & 2.33 & $<0.01$ \\
\hline $\begin{array}{l}\text { 9. I rather work alone than with people I } \\
\text { disagree with. }\end{array}$ & 2.10 & $<0.01$ \\
\hline $\begin{array}{l}\text { 10. I would rather join a group in which } \\
\text { there are no disagreements. }\end{array}$ & 2.37 & $<0.01$ \\
\hline $\begin{array}{l}\text { 11. I do not like when I disagree with } \\
\text { people. }\end{array}$ & 2.62 & $<0.01$ \\
\hline $\begin{array}{l}\text { 12. If I have a choice, I end the } \\
\text { conversation when disagreement occurs. }\end{array}$ & 2.97 & $<0.01$ \\
\hline $\begin{array}{l}\text { 13. I avoid talking to people who, in my } \\
\text { opinion, would not agree with me. }\end{array}$ & 2.98 & $<0.01$ \\
\hline 14. I enjoy disagreeing with people. & 1.33 & $<0.01$ \\
\hline $\begin{array}{l}\text { 15. Disagreement encourages debate and } \\
\text { continuation of communication. }\end{array}$ & 0.87 & $>0.01$ \\
\hline Flexibility total score & $<0.01$ \\
\hline Avoiding disagreement total score & 2.31 \\
\hline Disagreement tolerance (total) & $\begin{array}{l}\text { Disagreement tolerance according to the } \\
\text { categories high, medium, low }\end{array}$ & $<.01$ \\
\hline
\end{tabular}

LEGEND: $\boldsymbol{Z}$ - Kolmogorov Smirnov test result; $\boldsymbol{p}$ - Conclusion error probability.

\section{A. Levels of Disagreement Tolerance}

We have also wanted to determine the level of disagreement tolerance among students of the Media university in Koprivnica. Descriptive statistics for variables flexibility, avoiding disagreement and disagreement tolerance can be seen in Table III.

Results outlined in Table III. show that the students of the Media university display medium level of disagreement tolerance $(M=45.02)$, but since according to the authors of the scale medium level of disagreement tolerance would be between 32 and 46, we can conclude that this is a very good result. Additionally we wanted to see how disagreement tolerance is distributed among our subjects, what can be seen in Table IV.

Results outlined in Table IV: imply that more than one third of the students of the Media university in Koprivnica achieved high scores in disagreement tolerance (37\%). Also, 60.9\% of the students have shown medium level of disagreement tolerance, whereas only $2.2 \%$ have shown low level.
TABLE III. DESCRIPTIVE STATISTICS FOR VARIABLES FLEXIBILITY, AVOIDING DISAGREEMENT AND DISAGREEMENT TOLERANCE

\begin{tabular}{|l|c|c|c|c|c|c|}
\hline \multicolumn{1}{|c|}{ Variable } & $\boldsymbol{M}$ & $\boldsymbol{C}$ & $\boldsymbol{D}$ & $\boldsymbol{m i n}$ & $\boldsymbol{m a x}$ & $\boldsymbol{s \boldsymbol { d }}$ \\
\hline $\begin{array}{l}\text { Flexibility } \\
\text { total }\end{array}$ & 21.41 & 21 & 20 & 11 & 32 & 3.69 \\
\hline $\begin{array}{l}\text { Avoiding } \\
\text { disagreement } \\
\text { total }\end{array}$ & 24.39 & 24 & 25 & 14 & 35 & 3.98 \\
\hline $\begin{array}{l}\text { Disagreement } \\
\text { tolerance total }\end{array}$ & 45.02 & 45 & 46 & 24 & 62 & 6.41 \\
\hline
\end{tabular}

LEGEND: $\boldsymbol{M}$ - Arithmetic mean; $\boldsymbol{C}$ - Central value; $\boldsymbol{D}$ - Dominant value; $\boldsymbol{m i n}$ - minimal value; $\boldsymbol{m a x}$ - maximal value; $\boldsymbol{s} \boldsymbol{d}$ - standard deviation.

TABLE IV. LEVELS OF DisAgREEMENT TOLERANCE StATISTICS

\begin{tabular}{|l|c|}
\hline \multicolumn{1}{|c|}{ Level } & Students Percentage \\
\hline High (score > 46) & $37.00 \%$ \\
\hline Medium (score between 32 and 46) & $60.90 \%$ \\
\hline Low (score < 32) & $2.20 \%$ \\
\hline
\end{tabular}

\section{B. Gender Differences Between Levels of Disagreement Tolerance}

We also wanted to see whether there are any differences in disagreement tolerance with regard to the gender. For that purpose we ran t-tests for determining differences between two independent groups. Results of the descriptive statistics and the t-test for total scores on flexibility, avoiding disagreement and disagreement tolerance with regard to the gender can be seen in Table V.

Results show that no statistically significant differences exist in total score on flexibility $(\mathrm{t}=1.05 ; \mathrm{df}=145 ; \mathrm{p}>0.01)$, avoiding disagreement $(\mathrm{t}=-1.11 ; \mathrm{df}=145 ; \mathrm{p}>0.01)$ and disagreement tolerance $(\mathrm{t}=1.29 ; \mathrm{df}=145 ; \mathrm{p}>0.01)$ with regard to the gender.

TABLE V. DESCRIPTIVE STATISTICS AND T-TEST FOR VARIABLES FLEXIBILITY, AVOIDING DISAGREEMENT AND DISAGREEMENT TOLERANCE WITH REGARD TO THE GENDER

\begin{tabular}{|c|c|c|c|c|c|c|}
\hline \multirow{2}{*}{ Variable } & \multicolumn{2}{|c|}{$M$} & \multicolumn{2}{|c|}{$s d$} & \multirow{2}{*}{$\begin{array}{c}t \\
d f= \\
145\end{array}$} & \multirow{2}{*}{$p$} \\
\hline & Female & Male & Female & Male & & \\
\hline $\begin{array}{l}\text { Flexibility } \\
\text { total score }\end{array}$ & 21.67 & 21.02 & 3.81 & 3.49 & 1.05 & $\stackrel{>}{0.01}$ \\
\hline $\begin{array}{l}\text { Avoiding } \\
\text { disagreement } \\
\text { total score }\end{array}$ & 24.09 & 24.83 & 3.99 & 3.95 & -1.11 & $\overrightarrow{0.01}$ \\
\hline $\begin{array}{l}\text { Disagreemen } \\
\text { t tolerance } \\
\text { total score }\end{array}$ & 45.58 & 44.19 & 6.42 & 6.36 & 1.29 & $\stackrel{>}{0.01}$ \\
\hline
\end{tabular}

LEGEND: $\boldsymbol{M}$ - Arithmetic mean; $\boldsymbol{s} \boldsymbol{d}$ - standard deviation; $\boldsymbol{t}$ - $\mathrm{t}$-test result; $\boldsymbol{p}$ - conclusion error probability; $\boldsymbol{d} \boldsymbol{f}$ - level of freedom.

\section{Age Differences Between Levels of Disagreement Tolerance}

Last we wanted to see whether there are any differences in disagreement tolerance with regard to the age. For that purpose we ran simple variance analyses which aim at determining differences between one or more independent groups. We eliminated the last age category (31-40) since only one subject fell into that category. The results of the descriptive statistics and the simple variance analyses for total scores on flexibility, 
avoiding disagreement and disagreement tolerance with regard to the age can be seen in Table VI.

Results show that there are no statistically significant differences in total scores on flexibility $(\mathrm{F}=0.66 ; \mathrm{p}>0.01)$, avoiding disagreement $(\mathrm{F}=0.18 ; \mathrm{p}>0.01)$ and disagreement tolerance $(\mathrm{F}=0.25 ; \mathrm{p}>0.01)$ with regard to the subjects' age.

TABLE VI. DESCRIPTIVE STATISTICS AND VARIANCE ANALYSIS F RATIOS FOR VARIABLES FLEXIBILITY, AVOIDING DISAGREEMENT FND DISAGREEMENT TOLERANCE WITH REGARD TO THE AGE

\begin{tabular}{|c|c|c|c|c|c|c|c|c|}
\hline Variable & & $M$ & & & sd & & & \\
\hline Age (years) & $\begin{array}{l}15- \\
20\end{array}$ & $\begin{array}{l}21- \\
25\end{array}$ & $\begin{array}{l}26- \\
30\end{array}$ & $\begin{array}{l}15- \\
20\end{array}$ & $\begin{array}{l}21- \\
25\end{array}$ & $\begin{array}{l}26- \\
30\end{array}$ & $F$ & $p$ \\
\hline $\begin{array}{l}\text { Flexibility } \\
\text { total score }\end{array}$ & $\begin{array}{l}21 . \\
67\end{array}$ & $\begin{array}{l}21 . \\
14\end{array}$ & $\begin{array}{l}20 . \\
38\end{array}$ & $\begin{array}{c}3.6 \\
6\end{array}$ & $\begin{array}{c}3.6 \\
8\end{array}$ & $\begin{array}{c}4.4 \\
1\end{array}$ & 0.66 & $\begin{array}{c}> \\
0.01\end{array}$ \\
\hline $\begin{array}{l}\text { Avoiding } \\
\text { disagreement } \\
\text { total score }\end{array}$ & $\begin{array}{l}24 . \\
48\end{array}$ & $\begin{array}{l}24 . \\
14\end{array}$ & $\begin{array}{l}24 . \\
88\end{array}$ & $\begin{array}{c}3.9 \\
2\end{array}$ & $\begin{array}{c}4.0 \\
4\end{array}$ & $\begin{array}{c}4.9 \\
4\end{array}$ & 0.18 & $\begin{array}{c}> \\
0.01\end{array}$ \\
\hline $\begin{array}{l}\text { Disagreemen } \\
t \text { tolerance } \\
\text { total score }\end{array}$ & $\begin{array}{l}45 . \\
19\end{array}$ & $\begin{array}{l}45 . \\
00\end{array}$ & $\begin{array}{r}43 . \\
50\end{array}$ & $\begin{array}{c}6.0 \\
9\end{array}$ & $\begin{array}{c}6.7 \\
1\end{array}$ & $\begin{array}{c}8.8 \\
0\end{array}$ & 0.25 & $\begin{array}{c}> \\
0.01\end{array}$ \\
\hline
\end{tabular}

\section{DISCUSSION FOR THE END}

Based on the results of the research we conducted among the students of the Media university in Koprivnica, it has been concluded that the students show medium level of disagreement tolerance $(\mathrm{M}=45.02)$, which is however closer to the high level (score between 32 and 46). More than one third of the subjects showed high level of disagreement tolerance (37\%), whereas $60.9 \%$ of the subjects have shown medium level of disagreement tolerance. The scores are not dependent on the age and gender of the subjects.

As it has already been said, the results of this research can serve: (a) as a helping tool for composing curriculums for courses which focus on communicology, especially for graduate and postgraduate journalism studies or as an addition to the entrance exam, and (b) as a helping tool for composing curriculums for international courses (our intention was to use for universities cooperation between Croatia, Albania, Turkey and Slovenia), especially for graduate and postgraduate join studies which focus on informatics and communicology.

Given that this research has been conducted on only one university (the Media university in Koprivnica) among all students of the university, and now we cannot form any definite conclusions about students' disagreement tolerance in general, but rather about disagreement tolerance of the students studying at the Media university. However, it would be interesting to compare our results with the results of the same or similar researches conducted on other universities in the Republic of Croatia or on other universities around the world.

\section{APPENDIX: DISAGREEMENT TOLERANCE QUESTIONNAIRE}

This questionnaire has been composed in order to measure the tolerance level of an individual toward other people when disagreeing with them. Questions: 1. It is interesting for me to join a debate in which there is a lot of disagreement. 2. I enjoy talking to people who have different standpoints than mine. 3. I do not like to participate in conversations in which there is a lot of disagreement. 4. I rather work in groups in which everyone shares the same views as I do, than in those in which people share different views and standpoints. 5. I believe that disagreement is generally useful. 6 . I would rather change the subject when it comes to disagreement. 7. I have a tendency toward creating disagreement because I believe it is useful. 8. I enjoy quarreling with people about things we disagree on. 9. I rather work alone than with people I disagree with. 10. I would rather join a group in which there are no disagreements. 11. I do not like when I disagree with people. 12. If I have a choice, I end the conversation when disagreement occurs. 13.I avoid talking to people who, in my opinion, would not agree with me. 14. I enjoy disagreeing with people. 15. Disagreement encourages debate and continuation of communication. (Instructions: "Please use the following legend in order to estimate the your own level of tolerance: $5=$ I fully agree; $4=$ I agree; 3 = I neither agree, nor disagree; 2 = I do not agree; 1 = I do not agree at all.")

\section{REFERENCES}

[1] J. Čačić-Kumpes, "Education and tolerance," Journal for General Social Issues. Zagreb, Vol. 5 No. 2 (22), pp. 307-319, March 1996. (references)

[2] D. Divjak, J. Težački, "Practising tolerance," 2010. Downloaded on the 2nd of June 2013 from: http://medskvz.org/novine/?p=880

[3] M. Krizmanić, V. Kolesarić, Tolerance in everyday life - the psychology of tolerance, Zagreb: Naklada Slap, 2005.

[4] J. C. McCroskey, "Tolerance for Disagreement Scale (TFD)," 2nd of Februar 2007. Downloaded on the 2nd of June 2013 from: http://www.jamescmccroskey.com/measures/tfd.htm

[5] J. J. Teven, V. P. Richmond, J. C. McCroskey, "Measuring tolerance for disagreement," Communication Research Reports, Vol. 15, pp. 209-217, 1998. (references)

[6] M. Trimarchi, L. L. Papeschi, "From tolerance to the acceptance of differences," Journal for General Social Issues. Zagreb, Vol. 5 No. 2 (22), pp. 321-329, March 1996. (references)

[7] General Assembly. United Nations (UN), "Resolution 1386 (XIV): Declaration of the Rights of the Child," 20th of November 1959. Downloaded on the 2nd of June 2013 from: http://www.unicef.org/lac/spbarbados/Legal/global/General/declaration_ child1959.pdf

[8] General Assembly. United Nations (UN), "Resolution 2200A (XXI): International Covenant on Economic, Social and Cultural Rights," 16th on Decemeber 1966. Downloaded on the 2nd of June 2013 from: http://www.ohchr.org/EN/ProfessionalInterest/Pages/CESCR.aspx

[9] General Conference. United Nations Organization for Education, Science and Culture (UNESCO), "Declaration of the Principles of Tolerance," 16th of Novemeber 1995. Downloaded on the 2nd of June 2013 from: http://www.unesco.org/webworld/peace_library/UNESCO/HRIGHTS/12 4-129.HTM 